\title{
DIRECTAR: TEACHING THE BASICS OF CINEMATOGRAPHY USING AUGMENTED REALITY AS LEARNING TOOL
}

\author{
by
}

\author{
Gonzalo Andres Arteaga Bastidas
}

Bachelor's degree in Film and Audiovisual Media, University of Cuenca, 2015

\author{
A Major Research Paper presented \\ to Ryerson University \\ in partial fulfillment of the \\ requirements for the degree of \\ Master of Digital Media in the \\ program of Digital Media
}

Toronto, Ontario, Canada, 2019

(C) Gonzalo Andres Arteaga Bastidas, 2019 


\section{AUTHOR'S DECLARATION}

I hereby declare that I am the sole author of this MRP. This is a true copy of the MRP, Including any required final revisions.

I authorize Ryerson University to lend this MRP to other institutions or individuals for the purpose of scholarly research

I further authorize Ryerson University to reproduce this MRP by photocopying or by other means, in total or in part, at the request of other institutions or individuals for the purpose of scholarly research.

I understand my MRP may be made electronically available to the public. 


\section{Abstract}

DIRECTAR: TEACHING THE BASICS OF CINEMATOGRAPHY USING AUGMENTED REALITY AS A LEARNING TOOL

Gonzalo Andres Arteaga Bastidas

Master of Digital Media

Ryerson University, 2019

This paper examines the development of an augmented reality app that will be used as a tool for people interested in learning the conventions of cinematography. Augmented reality has demonstrated its value in various aspects of education, from helping highschoolers learn abstract concepts of chemistry, to medical and nursing training. DirectAR merges augmented reality with tried and tested visual language concepts in order to give its users a hands-on learning experience. This is possible due to the creation of AR characters that serve as models with which users of this app are able to grasp concepts by actually putting them into practice. 


\section{ACKNOWLEDGEMENTS}

I would like to express my sincere gratitude and admiration to Dr. Richard Lachman for providing us with thought provoking lectures during first semester, and most importantly, for his support and guidance through every step of this MRP. I would also like to Thank Asma Arslan, for taking the time to be our second reader and giving us her insight to take our user experience a step further. I would also like to thank Ahmed Sagarwala and Lissa Quaglia for their support since the day I applied to the program. I am very grateful for the opportunity to come to this country and the people l've met. None of this would have been possible without the support of family, especially my mother, Patricia. 
AUTHOR'S DECLARATION. ii

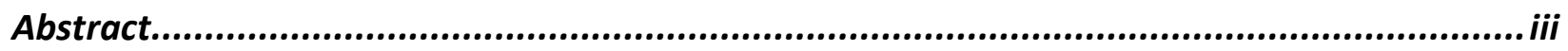

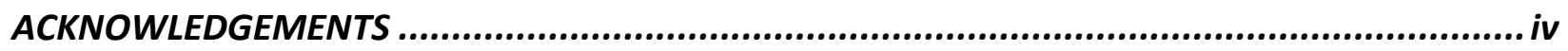

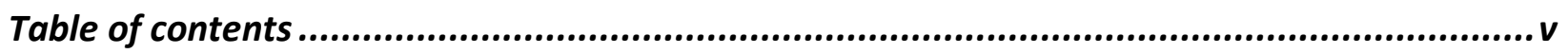

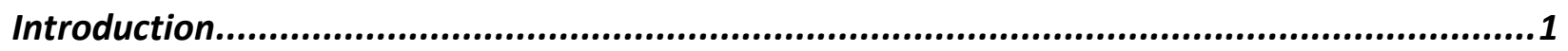

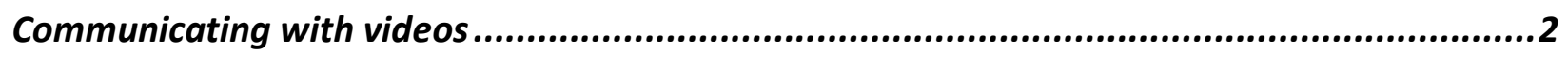

Learning cinematography: Traditional approaches and new opportunities ............................4

Augmented reality as a tool to learn cinematography .......................................................

Direct AR lesson 1: Framing characters........................................................................

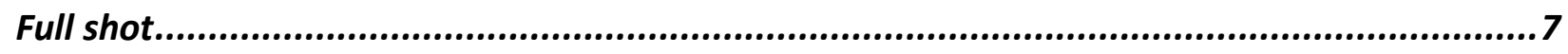

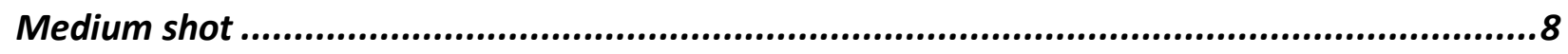

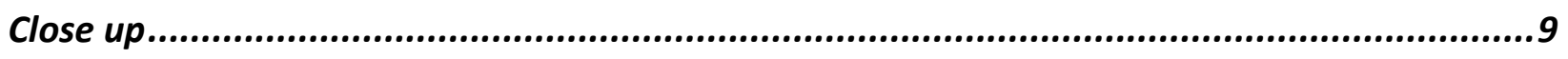

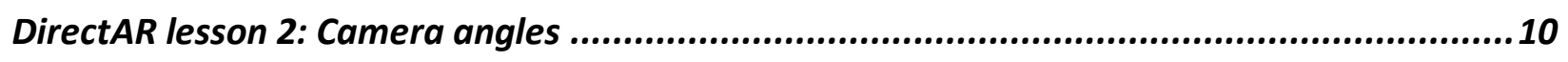

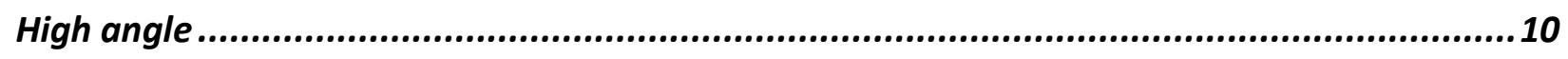

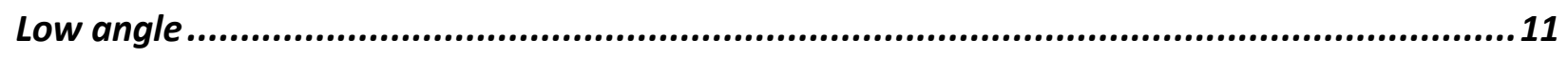

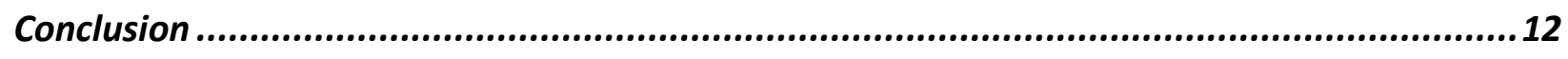





\section{Introduction}

At the heart of cinematography exist a series of rules and conventions that have been universally held by creators as the building blocks of visual language including (but not limited to): composition, camera movements and lighting (Lancaster, 2012). And while the word rule might generate immediate negative reactions, it has been proven time and again that when it comes to visual storytelling, learning the rules and conventions is

necessary before one begins to break them and pave the way for innovation. (Brown, 2012).

The nature in which audiovisual content is created has radically changed in recent years as a result of the revolution of DSLR cinematography. Phillip Bloom, a renowned cinematographer remarks, "Suddenly we are giving people an affordable a tool to make high-quality imagery, and it's releasing potential in people they never realized they had", (qtd. In Lancaster, 2012). In this way, DSLR democratized access to tools that had one been reserved to a small segment of the population that could afford them. Smartphones took this a step further by providing users with the ability to record and store video with their devices. This has also been accompanied by the success of online distribution platforms like Vimeo or Youtube that have made possible to expose this new wave of audiovisual 
creation. However, Teaching about visual storytelling entails much more than the technical aspects of operating a camera, and having access to the latest equipment is not a guarantee for the creation of enticing visual narratives.

The next step in this evolution has been largely propelled by the emergence of high quality cameras and sensors embedded in mobile phones. Because sharing images is such an integral element of social media, even mid-range mobile phones are now equipped with good quality cameras. This does not mean that telling a story using a camera has gotten easier, only more accessible. Stephen Soderbergh, an A-list hollywood director shot one of his most recent films using an Iphone. In an interview with The Hollywood Reporter he remarks about his experience: "You still need to know how to stage something, but it's a pretty incredible tool", (qtd. Swart, 2019). Direct AR will attempt to bridge the democratizing technology in mobile phone cameras to empower its users with the knowledge so they can know the basis of visual language paradigms.

\section{Communicating with videos}

In today's world, most smartphone users will have access to a camera that has the capability of recording decent quality video. A study by the Pew Research Center found that in 2019 an estimated 5 billion people around the world have a mobile phone, with over half of these devices being smartphones, (Taylor \& Silver, 2019).This has had an effect in the production of amateur video. A good way to measure the increase in video 
production is to look at YouTube statistics. According to Brandwatch, 400 minutes of videos are uploaded to YouTube every minute. (Smith, 2019). While the amount of videos produced around the world and uploaded on this platform may be staggering, the same cannot be said about the esthetic qualities of these videos. It is undeniable that smartphone videography keeps getting better in terms of equipment, such as better sensors and lenses, yet the practice of capturing life through a lens has evolved into a mundane and carless act. A good example of this are concerts. While people will go out of their way to capture some of the experience on video, the results are usually grainy images with saturated sound that may be shared on a social media platform. Yet people still do this as a way to try and capture a moment in their lives: the result of the recording might be low quality but there is a strong emotional impulse behind this act.

Social media has played a very large part in the democratization of video production as it acts as a showcase that allows creators to connect with an audience, which may be composed of friends and family or millions of viewers as viral videos have shown. Another study conducted by the Pew Research Center showed that $54 \%$ of internet users post photos and videos online that they have taken themselves. (Duggan, 2013). Platforms like Instagram and Snapchat are primarily focused on image sharing while other social media platforms have tried to emulate certain practices like the ability to create stories. At the very core, these new forms of communication through video still can be traced back to a more traditional approach of filmmaking as they aim to convey a moment, information or an emotion through moving images. The result of this are social media outlets that are being redefined by consumer video production and curation. 


\section{Learning cinematography: Traditional approaches and new opportunities}

In a traditional setting, namely, film schools and higher learning institutes, the approach to learning cinematography is usually affected by the resources and number of students in each class. If the equipment is sufficient, the student will get a chance to learn about image composition by actually putting the theory learned into practice. In other school settings the amount of students is greater than the equipment the institution owns. In this kind of setting learning composition might be limited to lectures where instructors present concepts exemplifying using movie clips, still photography and diagrams. Another stage of the traditional learning process might be to practice the concepts learned in class by producing student films. While this is a very effective way to expose an aspiring filmmaker to a professional working environment, it may also not be accessible to everyone.

Direct Ar guides students through basic lessons in cinematography not only by presenting a concept, but also giving them the chance to experience it immediately using curated lessons. The users will first be greeted by an information box that gives a general overview of the lesson. The user will then proceed to interact with the AR character using their phone's camera. The idea is to guide the students to achieve a specific type of frame or movement, once that frame is reached, an animation is triggered that suggests to the user the expressive nature of the frame they are using.

The user also gets a visual prompt of the type of frame they are currently producing. 


\section{Augmented reality as a tool to learn cinematography}

Augmented reality is still in an emerging stage. In recent years it has found success in various aspects of daily life from video games with examples like Pokemon GO (Niantic, Inc, 2016) or Dance Reality (Dance Reality, 2019), an AR app designed to teach users different dance styles . Education has also been fertile ground for augmented reality tools to develop and be introduced in classrooms, aiding teachers find compelling options to transmit knowledge in a variety of subjects from astronomy (Kerawalla et al, 2006) to environmental investigation, (Kopler \& Squire, 2007).

For the purpose of this analysis, Augmented Reality will be defined as the coexistence of virtual objects and real environments that allow learners to visualize complex spatial relationships and abstract concepts. (Arvanitis et al, 2007). In this case, we will use a smartphone's camera and recording functions. Cinematography and visual language relate to this definition as they are also built upon the relationships of space and objects through the application of abstract concepts like movement, balance, rhythm and contrast.

There is a lot of common ground in cinematography teaching styles as it is based on visual language theory established through many centuries and present in various artistic expressions (Jacobs, 2011). Usually one of the basic lessons will have to do with the principles of image design through the placement of objects and people within a frame (Freeman, 2007). Whether it is learned through textbooks, tutorial videos or in a higher 
learning institution, these approaches can find limitations when translating theoretical knowledge to practice. This may be a product of the absence of hands-on approach to learning cinematography that is usually the consequence of a lack of resources - for example, learning institutions that tend to teach using expensive, high-end cameras in limited numbers.

Resources for a cinematography student are not only limited to equipment. In order to practice, a student may also need to work with a subject or actor. It is only then that they will be able to fully grasp the relationship between the different elements of an image. This is especially the case with character shots such as wide, medium and close ups. Fortunately, augmented reality can provide a solution by supplying synthetic 3D characters, (Hsin-Kai Wu et al, 2012). These characters will give learners the chance to practice cinematographic concepts in a controlled environment, using a far more accessible tool and without having to depend on the disposition of another person to practice with.

DirectAR presents a holistic approach to learning cinematography. It will demonstrate key concepts by inciting the user to put them into practice. Kurt Lancaster states, "Don't break the rules until you know how to use each of them well", (Lancaster, 2012). DirectAR's first two lessons will focus on the principles of character framing and camera angles as the first building blocks of composition. The reasoning behind this is that character framing is 
an effective way to demonstrate the emotive and narrative power that a cinematographer can give to an image with a simple premise like how close the camera is to a subject.

\section{Direct AR lesson 1: Framing characters}

Image composition is a key element in cinematographic language. It refers to the arrangement of the setting, objects and characters in a frame to transmit information or convey an idea or emotion. And while composition comprises of much more than just character framing, this practice could be considered to be its building blocks. In Blain

Brown's words: "If we think of a language of cinema, these shots are the vocabulary" (Brown, 2012). While there is a large variety of shots, for the first lesson in the DirectAR course three main types of shots will be taught: Full, medium and close shots. These three shots are a good showcase of visual storytelling by only using the distance between the camera and subject. A full shot can be used to establish a scene, medium shots are regularly used when filming conversations and close shots have a great emotional charge and are a good way to portray emotions and conflict.

\section{Full shot}

A wide shot is usually used to establish certain aspects of a scene like the setting and the characters that will be involved in it. Blain Brown remarks "The wide shot is any frame that encompasses the entire scene. This makes is all relative to the subject". (Brown, 2012). This means that the frame will adjust to the setting whether this 
be a small city room or a giant prairie. However, it will always try to encompass the whole scene and therefore contain a large amount of information. A wide shot is useful to display contextual information about a character and the scene, for example, time of

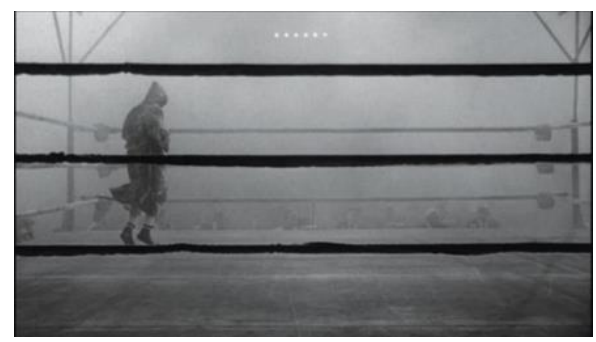
day and location, but it can also go into other aspects of a scene such a depicting the socioeconomic condition, past history and conflict of a character.

Firgure 1: Raging Bull, 1980

In Direct AR, the user will be guided by a prompt on the phone's screen alerting them that they have successfully framed the character within the parameters of a wide shot, this then triggers the character to animate and request the user to move in closer to reach the next frame.

\section{Medium shot}

A medium shot is a good way for filmmakers to bring the attention of the audience closer to the characters while still displaying their surroundings. This shot is often referred to as a waist shot as this is the area of physical coverage with this type of framing. Medium shots tend to be used when filming conversations between characters as it allows the audience to get more involved with the facial expressions and body language of the characters without focusing on specific details. 


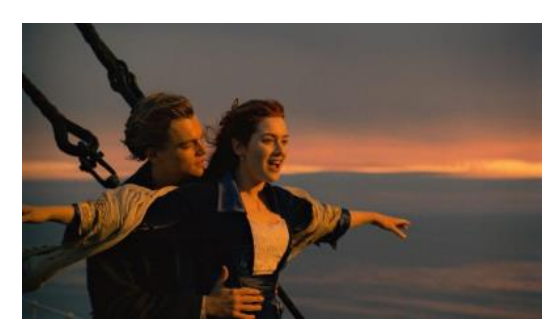

In the app, a visual prompt will alert the user that a medium shot has been reached, after a few seconds an animation will be triggered in the AR character inviting the user to move in closer to achieve the third and final shot on the lesson.

Figure 2: Titanic, 1997

\section{Close up}

This type of shot can have many variations depending on how the cinematographer has decided to frame the image. It will usually comprise of the character's top of the head and end at the shoulder line. Variants include choker shots which will go from the characters head to the throat or an extreme close up which will focus on a detail on the characters face such as its eyes or lips. Blain Brown states: "Close-ups are one of the most important shots in the vocabulary". (Brown, 2012). The reason for this is the vast

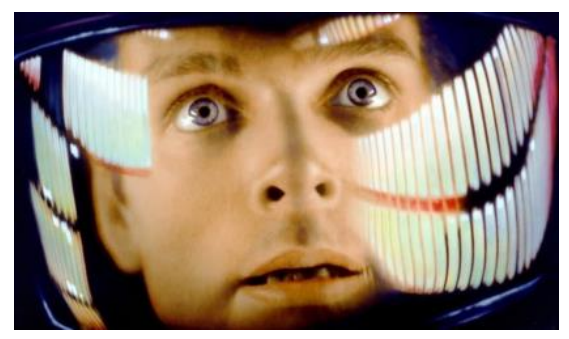
expressive value that they possess. Closing up to a characters will reveal the actors facial expressions and, in doing so, act as a vehicle for the transmission of emotions progression of a story.

Figure 3: 2001: A Space Odyssey, 1968

While the blockbuster film has brought fantastic worlds and extravagant characters to life, no amount of CGI has been able to replace the striking power of human emotion. After all, if cinema was to be simplified to its most rudimentary elements they would be human action and reaction. 
In Direct AR, once the user has reached a medium shot, the animated character will prompt them to move in closer until a close shot is achieved. This will conclude the first lesson.

\section{DirectAR lesson 2: Camera angles}

Another vital element of image composition has to do with the placement of the camera in relation to the height of an object or the eye level of a character. Although these may appear to be simple premises, once again, they are charged with creative and narrative potential. Variations from eye level have filmscape implications, psychological undertones and are useful as strictly compositional device, (Brown, 2012). DirectAR's second lesson will contain two camera angles: high and low.

\section{High angle}

These types of shots are usually used to establish dominance over a character or a situation. This may be used as a narrative tool, for example to portray the weakness of a character. It may also be used to expose and establish the setting in which the scene is taking place (Brown, 2012). 
In the app, the user is greeted by a visual prompt that explains the lesson and invites them to experiment moving the camera in different angles. Once a high angle is achieved, an animation and visual prompt will be triggered making the AR character act

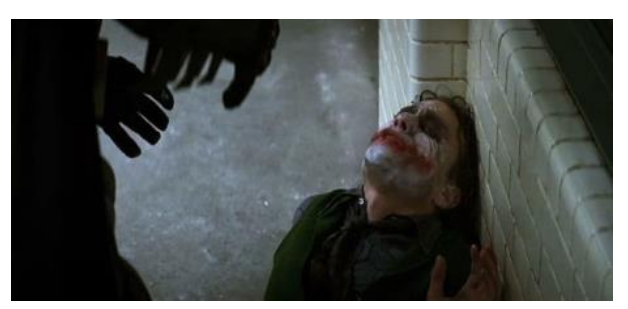

submissive and weak. While this is a caricature of the narrative effect that a high angle can have, it is an effective way to transmit this knowledge to the user.

Figure 4: The Dark Knight, 2008

\section{Low angle}

This type of framing will have the opposite effect of the angle aforementioned, at the very basis it can be used to portray the supremacy of a character over others but it also holds richer meanings. When a character is approaching something as seen from a low angle, little is revealed beyond what the character might see himself, this puts the audience closer to the mindset of the character. This type of framing is used in horror movies where the scare is usually shared by the characters on screen and the audience in the theater. (Brown, 2012). By using a concept as simple as placing a camera at a

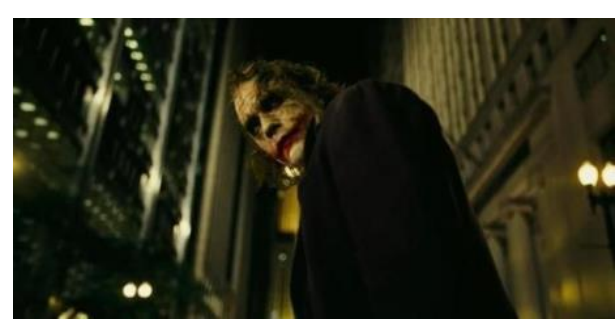

certain angle, a cinematographer can entice the audience by managing the information they receive and effectively, immersing them in the mind of a character.

Figure 5: The Dark Knight, 2008

In DirectAR the user will be prompted to experiment using different camera angles, when a low angle is reached a visual prompt and animation will trigger making the AR character act in a menacing way. 


\section{Conclusion}

Augmented reality presents a great opportunity to develop new educational tools for aspiring filmmakers and cinematographers. These tools can help bridge the gap between the intake of theoretical knowledge and actual hands-on practice with the use easily available devices such as smartphones. DirectAR will aim to become one of these instruments by providing it's users with augmented reality characters that will serve as subjects with which to practice. The first demo will contain two basic lessons as a way to showcase the concepts behind this application. This is only the start as other lessons are planned to be developed in the near future covering other varieties of character frames, camera movements and lighting. While the main target for this project are aspiring video and film creators, DirectAR intends to demonstrate to any user that endless avenues of creativity can be unlocked by applying basic cinematographic premises to their smartphone's camera. 


\section{Bibliography}

Brown, Blain. (2011). Cinematography: Theory and Practice, Taylor \& Francis Group. ProQuest Ebook Central,https://ebookcentral-proquest-com.ezproxy.lib.ryerson.ca/lib/ryerson/detail.action?doclD=72 0723.

Cameron, J, Laundau, J (Producers), Cameron, J (Director). (1997), Titanic [motion picture]. USA: Paramount Pictures

Danakorn, N, (2013, November, 16), Mobile Augmented Reality: The potential for educationl. Retrieved on July 28th, 2019, from, https://www.sciencedirect.com/science/article/pii/S1877042813038305\#bibl0005

Dance Reality LLC, (2019), Dance Reality. Seattle, WA: Dance Reality

Thomas, E, Roven, C, Nolan, C (producers), Nolan, C (Director). (2008), The Dark Knight [motion picture]. USA: Warner Bros. Pictures

Duggam, M, (2013, October, 18). Photo and video sharing grow online. Retrieved on July 28th, 2019 from, https://www.pewinternet.org/wp-content/uploads/sites/9/media/Files/Reports/2013/PIP_Photos-andv ideos-online_102813.pdf

Freeman, M, (2007), The Photographer's Eye, Oxford, Focal Press

Jacobs, S. (2011). Framing pictures and the visual arts. Edinburgh: Edinburgh Scholarship Online Lancaster, K. (2012). DSLR Cinema : Crafting the Film Look with Large Sensor Video, Routledge, ProQuest Ebook

Central,https://ebookcentral-proquest-com.ezproxy.lib.ryerson.ca/lib/ryerson/detail.action?doclD=10 92831.

Niantic, (2016), Pokemon Go. San Francisco, CA: Niantic

S, Kubrick (Producer), S, Kubrick (Director). (1968), 2001: A Space Odyssey [motion picture]. USA: Stanley Kubrick Productions

Swart, S. (2019, January 1). Slamdance: Stephen Soderbergh talks about filming 'High Flying Bird' With an Iphone. Retrieved July, 28th, 2019 from, https://www.hollywoodreporter.com/news/steven-soderberghinterview-iphone-netflix-why-his-retirem ent-didnt-take-1179541

Smith, K (2019, July, 15). 52 fascinating and incredible YouTube statistics. Retrieved July 28th, 2019 from, https://www.brandwatch.com/blog/youtube-stats/

Taylor, K \& Silver, L (2019, February, 5). Smartphone ownership is growing rapidly around the world, but not always equally. Retrieved July 28th, 2019 from, https://www.pewresearch.org/global/2019/02/05/smartphone-ownership-is-growing-rapidly-around-th eworld-but-not-always-equally $/$

The Telegraph. (2010, April 1). YouTube: a history. Retrieved July, 28th, 2019 from, https://www.telegraph.co.uk/finance/newsbysector/mediatechnologyandtelecoms/digital-media/7596 636/YouTube-a-history.html 
Winkler, I, Chartoff, R (Producers), Scorcese, M (Director). (1980), Raging Bull [motion picture]. USA: United Artists

Wu, H, et al, (2012, October, 26), Current status, opportunities and challenges of augmented reality in education. Retrieved on July 28th, 2019, from, http://citeseerx.ist.psu.edu/viewdoc/download?doi=10.1.1.644.8231\&rep=rep1\&type=pdf\&fbclid=IwA R1ER5Vs_EFQ0VhqLGN3D1Ai3n2UCv-U7onRu-WFHJx4ALT_w_SFmWdjoTY 